\title{
Physiological Aspects of Vestibular Schwannoma Treated with Radiosurgery
}

\author{
Yoshihisa Kida ${ }^{1 *}$ and Takaharu Yamauchi ${ }^{2}$ \\ ${ }^{1}$ Gamma Knife Center, Okuma Hospital, Nagoya, Japan \\ ${ }^{2}$ Clinical Laboratory Department, Okuma Hospital, Nagoya, Japan
}

*Corresponding author: Yoshihisa Kida, Gamma Knife Center, Okuma Hospital,

2-9-34, Ohzone, Kitaku, Nagoya, Japan.

Received Date: February 16, 2021

Published Date: March 01, 2021

\begin{abstract}
Disequilibrium is one of the most popular symptoms of vestibular schwannoma, next to the hearing disturbance and tinnitus. In our institute, the cases with vestibular schwannoma were concurrently investigated with neurophysiological studies like pure tone hearing of Gardner-Robertson method (GR), auditory brainstem response (ABR), vestibular evoked myogenic potential (VEMP) and Stabilometry. Among them, VEMP study gives us the most valuable informations. In fact, both qualitative and quantitative improvements of VEMP have been verified in association with the symptomatic recovery of disequilibrium.
\end{abstract}

Keywords: Acoustic tumor; Disequilibrium; Dizziness; Gamma knife; Physiological study; Radiosurgery; Vestibular schwannoma; VEMP

\section{Introduction}

Vestibular schwannomas have been considered to be a one of the best indication for radiosurgery. In reality, tumor control after gamma knife treatment are reportedly very excellent. In spite of excellent tumor control, functional outcomes like hearing ability are not so great. Hearing preservation have been achieved mostly for the cases within normal range at the first radiosurgery. Persistent disequilibrium is the another problem for the patients before and during follow-up period.

\section{Clinical Cases and Methods}

Among 50 cases treated in our institute since July 2016, the most popular symptoms at the radiosurgery are hearing disturbances including hearing loss, tinnitus or sudden deafness (Figure 1). In addition, dizziness, vertigo, ataxia and floating sensation are known to be next familiar symptoms of this disease. In addition to the radiological studies with CT or MRI, the functional studies after radiosurgery, like pure-tone hearing study (G-R), auditory brainstem response (ABR), vestibular evoked myogenic potential (VEMP), stabilometry are routinely performed. After the initial study at the radiosurgery, the subsequent examinations are carried out periodically with every 3 to 6 month intervals.

\section{Results}

In first 50 cases treated in our hospital, hearing disturbance with G-R study is most remarkable. In the studies with ABR, low amplitude of the affected side is prominent in many cases and delayed propagation time from I to $\mathrm{V}$ waves are often noted. The specific changes of VEMP are available in many cases, chiefly in terms of delayed latency of P13, and the decreased amplitude, which is estimated by the hight from the bottom of P13 to the top of 
N23 as shown in (Figure 2). Subsequent changes of latency of P13 as well as the amplitude are marked in many cases. These changes are often moving parallel to the recovering clinical symptoms like dizziness, floating sensation and ataxia, as shown one example in (Figure 3) (Table 1).

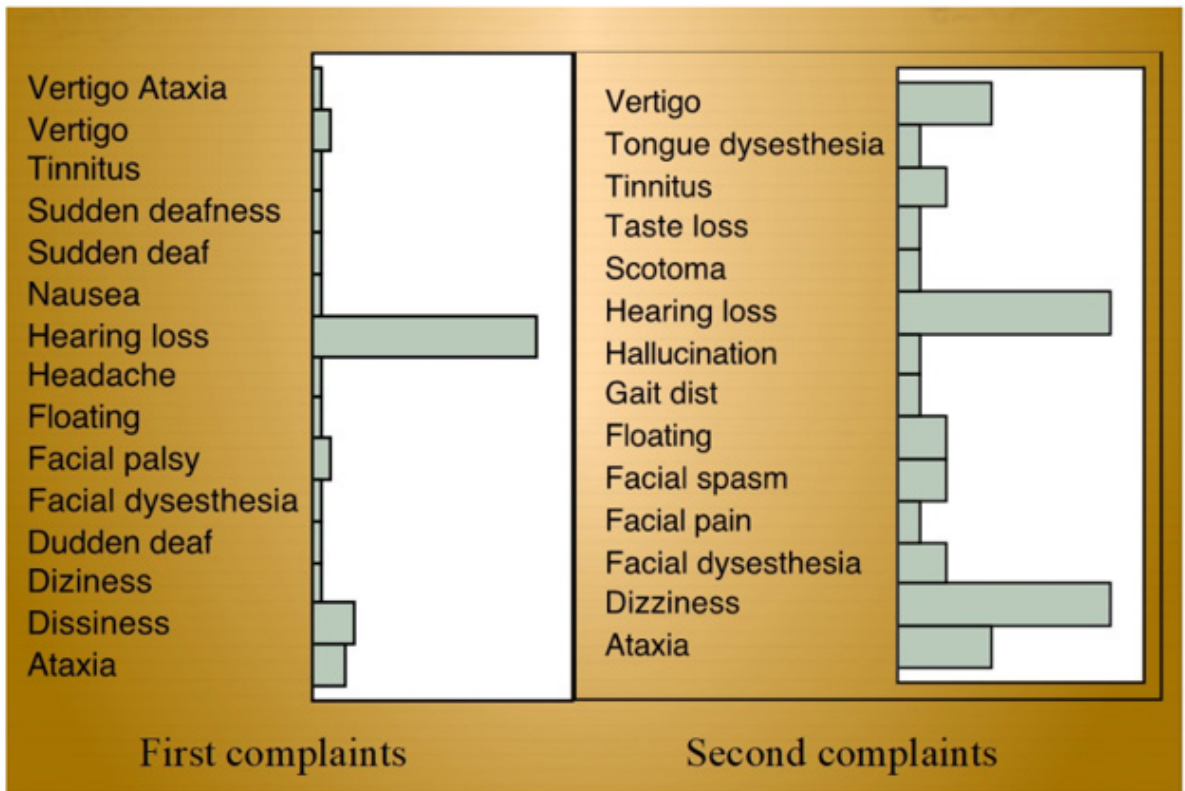

Figure 1: First and second symptoms of the patients with vestibular schwannomas at radiosurgery.

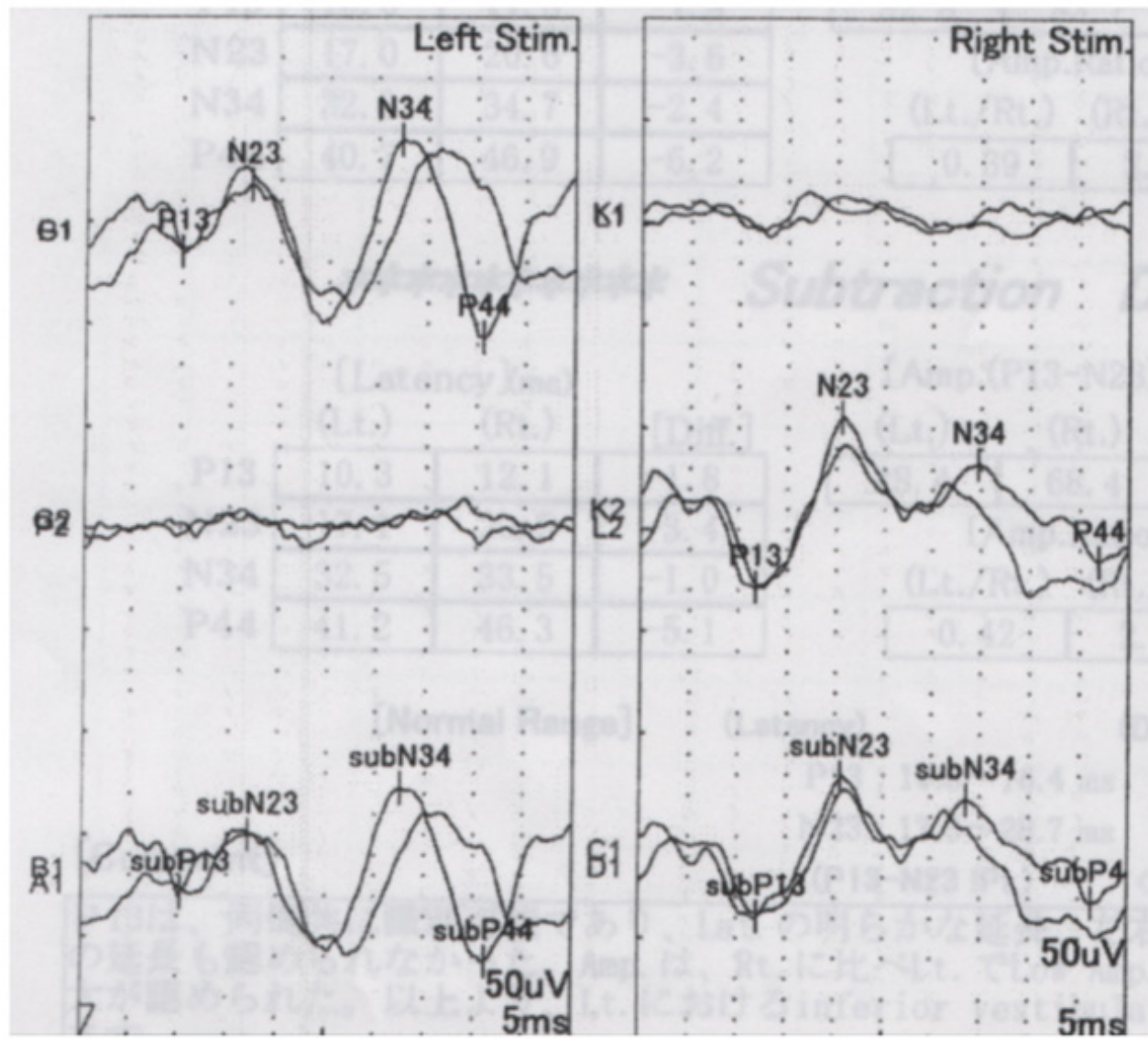

Figure 2: Vestibular evoked myogenic potential (VEMP) study. Latency of P13 and amplitude between P13 to N23 are illustrated. 


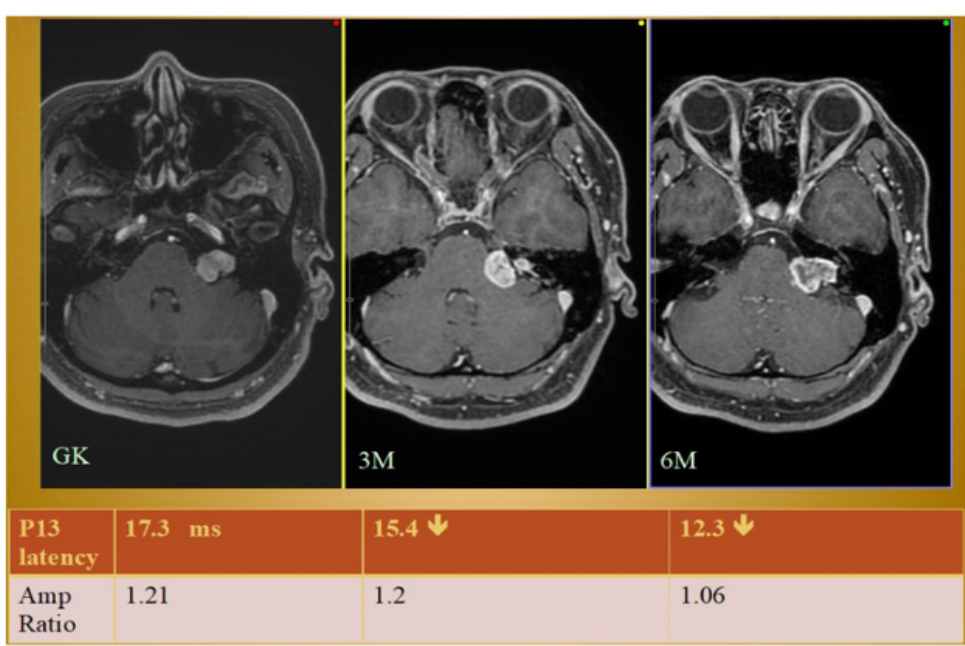

Figure 3: An example of vestibular schwannoma treated with gamma knife. In spite of non-recognizable improvement of hearing, latency of P13 improved and the amplitude recovered, apparently according to the recovering dizziness. Although MRIs showed no apparent tumor shrinkage, a finding of moderate central tumor necrosis become clear.

Table 1: Summary of the finding of physiological studies. Pure tone hearing and ABR were not significantly improved. Conversely, VEMP study demonstrated a remarkable recovery of p13 latency.

\begin{tabular}{|c|c|c|c|c|}
\hline Methods & Evaluation & At GK & 3-6 months & 7-12 months \\
\hline $\begin{array}{l}\text { 1) Pure tone hearing } \\
\text { (Gardner-Robertson) }\end{array}$ & $\begin{array}{l}\mathrm{N}: \text { Hearing }> \\
30 \mathrm{~dB}\end{array}$ & Mean 69.9 dB (44 cases) & Mean 73.1 dB (30 cases) & \\
\hline $\begin{array}{l}\text { 2) Auditory Brainstem Response } \\
\text { (ABR) }\end{array}$ & Transmission I-V & $\begin{array}{l}\text { Normal (13) Delayed (10) Low } \\
\text { amplitude (9) (Normal: } 40.6 \% \text { ) }\end{array}$ & $\begin{array}{c}\text { Normal (6) Delayed (7) Low } \\
\text { amplitude (8) (Normal: } \\
28.6 \%)\end{array}$ & \\
\hline $\begin{array}{l}\text { 3) Vestibular evoked myogenic } \\
\text { potential (VEMP) }\end{array}$ & $\begin{array}{l}\text { Latency P13 Am- } \\
\text { plitude P13-N23 }\end{array}$ & $\begin{array}{c}\text { Normal (7) Delayed (16) Normal } \\
\text { (15) Decrease (8) (Normal 7/46: } \\
15.2 \%)\end{array}$ & $\begin{array}{l}\text { Normal (15) Delayed (6) } \\
\text { Normal (13) Decrease (8) } \\
\text { (Normal 15/42:46.9\%) }\end{array}$ & $\begin{array}{c}\text { Normal (8) Delayed (2) } \\
\text { Normal (4) Decrease } \\
\text { (6) (Normal 8/20: } \\
40 \%)\end{array}$ \\
\hline 4) Stabilo-metry & $\begin{array}{l}\text { Trail Dimension } \\
\text { Romberg ratio }\end{array}$ & $\begin{array}{c}\text { Normal (14) Increase (11) Normal } \\
\text { (20) Increase (7) }\end{array}$ & $\begin{array}{l}\text { Normal (11) Increase (11) } \\
\text { Normal (17) Increase (5) }\end{array}$ & \\
\hline
\end{tabular}

\section{Conclusion}

The most popular symptoms of vestibular schwannoma are the hearing impairment and related signs. However, many patients are often suffering from disequilibrium before and after the treatment [1-4]. Functional studies with hearing ability, ABR and VEMP, Stabilometry may indicate the serial changes of neurophysiological function [5]. Special importance is the findings with VEMP study, indicating the effects of radiosurgery better than those after microsurgery $[6,7]$. Since the P13 is readily and constantly captured, these objective changes can be detected quantitatively after radiosurgery, which may be more accurate than the subjective evaluation with Dozziness Handicap Inventry (DHI) [8]. In conclusion, neurophysiological studies show us various functional informations after radiosurgery. Among them, VEMP study demonstrates the changing and improving function of disequilibrium clearly.

\section{Acknowledgement}

None.

\section{Conflict of Interest}

No conflict of interest.

\section{References}

1. Dayal M, Perez Anjugar A, Chuang C, Parsa AT, Barani IJ (2013) Management of vestibular schwannoma: focus on vertigo. CNS Oncol 2(1): 99-104.

2. Von Kirschbaum C, Gurkov R (2016) Audiovestibular function deficits in vestibular schwannoma. Biomed Res Int 4980562

3. Wackym PA, Hannley MT, Runge-Samuelson CL, Jensen J Zhu YR (2008) Gamma knife surgery of vestibular schwannomas: longitudinal changed in vestibular function and measurement of the Dizziness Handicap Inventry. J Neurosurg 109: 137-143

4. Stavas MJ, Matthew, Carlson ML, Attia A, Jacobson GP, et al. (2014) Does radiation dose to the vestibule predict changes in balance function and patients perceived dizziness following stereotactic radiotherapy for vestibular schwannoma? Am J Otolaryngol 35(5): 565-571.

5. Ojala M, Palo J (1991) The aetiology of dizziness and how to examine a dizzy patient. Ann Med 23(3): 225-230.

6. Lynn SG, Driscoll CL, Harmer SG, Beatty CW, Atkinson EJ (1999) Assessment of disequilibrium after acoustic neuroma removal. Am J Otol 20(4): 484-494. 
7. Uehara N, Tanimoto H, Nishikawa T, Katsunuma S (2011) Vestibular dysfunction and compensation after removal of acoustic neuroma. Vestib Res 21(5): 289-295.
8. Wackym PA, Hannley MT, Runge-Samuelson CL, Jensen J, Zhu YR (2008) Gamma knife surgery of vestibular schwannomas: longitudinal changes in vestibular function and measurement of the Dizziness Handicap Inventory. J Neurosurg 109:137-143. 